\title{
POSTPRINT
}

\section{'These psychiatrists rate themselves as gods': Disengagement and engagement discourses of people living with severe mental illness}

\author{
MIKE CHASE ${ }^{1}$, JÖRG ZINKEN ${ }^{1}$, ALAN COSTALL' ${ }^{1}$, JAY WATTS'2, STEFAN PRIEBE ${ }^{3}$ \\ (1) University of Portsmouth, Portsmouth, UK (2) City University, London, UK (3) Newham Centre for Mental Health, \\ London, UK
}

\begin{abstract}
Positioning analysis, a variant of discourse analysis, was used to explore the narratives of 40 psychiatric patients (11 females and 29 males; mean age $=40$ years) who had manifest difficulties with engagement with statutory mental health services. Positioning analysis is a qualitative method that captures how people linguistically position the roles and identities of themselves and others in their day-to-day lives and narratives. The language of disengagement incorporated the passive positioning of self in relation to their lives and treatment through the use of metaphor, the passive voice and them and us attribution, while the discourse of engagement incorporated more active positioning of self, achieved through the use of the personal pronoun we and metaphoric references to balanced relationships. The findings corroborate previous thematic analysis that highlighted the importance of identity and agency in the 'making or breaking' of therapeutic relationships (Priebe et al. 2005). Implications are discussed in relation to how positioning analysis may help signal and emphasize important life and therapeutic experiences in spoken narratives as well as clinical consultations.
\end{abstract}

Keywords: mental illness; disengagement; mental health services; discourse analysis; positioning analysis; identity

\section{Introduction}

For many people living with severe mental illness there is a significant and strong association between disengagement from mainstream treatment and services and adverse outcomes (Fenton et al. 1997; O'Brien et al. 2008). In general it is acknowledged that people with severe mental illness who disengage from treatment and services tend to have an increased risk of social isolation, suicide, homelessness, and a greater number of in-patient days (Mueser et al. 1998). For example, a review of suicide incidences between 1996 and 2001 found that one third of people with severe mental illness who committed suicide had missed their last outpatient appointment with health professionals (Department of Health 2001).

Why people disengage from mental health services and what, if anything, makes them want to re-engage, are essential issues for both clinical practitioners and commissioners. To date, research efforts in this area have tended to use quantitative methods, exploring research questions related to mental health services attrition and non-attendance and the types of service configuration and patient characteristics that may lead to better therapeutic outcomes (O'Brien et al. 2008). For example, the UK 700 study addressed whether the caseload of professionals had an effect on outcomes such as inpatient days, quality of life and housing stability (Burns et al. 1999), while Priebe et al. (2003) explored how socio-demographic and other patient characteristics affected these outcomes. However, the underlying psychosocial factors that facilitate or inhibit people's engagement with mental health services remain poorly understood.

In order to make better sense of this complex phenomenon, researchers are beginning to turn to qualitative research (Sainsbury Centre for Mental Health 1998; Priebe et al. 2005). In contrast to more standardized and structured quantitative procedures, qualitative methods offer a broad range of analytical approaches that have the potential to delve deeper into research questions that incorporate everyday psychosocial experiences of mental health, including interactions with institutional practices (Williams 2002; Slade and Priebe 2006). 
Priebe et al. (2005) used grounded thematic analysis to explore the social and personal contexts that led to the disengagement from mental health services by people who had a fragmented history of engagement, and to define what context, if any, surrounded any re-engagement. In the grounded thematic approach, themes are encouraged to emerge inductively from the participants' interviews, rather than being deductively led by a priori codes or hypotheses (Strauss and Corbin 1998; Braun and Clark 2006). Through this method, Priebe et al. (2005) identified that the interrelated themes of identity and agency played an integral part in disengagement. The participants, who had manifested difficulties in engaging with mental health services, consistently made efforts to cling on to the lives they knew or remembered and to reject anything that might facilitate the transition to a perceived identity of passivity or 'patienthood', e.g. the power differentiated therapeutic relationships, the debilitating side effects of medication or the adoption of confining and stigmatizing diagnostic labels. Conversely, paramount to the engagement process was the investment of time and commitment into partnership models of care, where therapeutic relationships moved away from a pure medical focus and encouraged people to be active participants in their treatment and lives.

The analysis in Priebe et al. (2005) focused upon the thematic content of the participants' narratives of disengagement. In our efforts to further develop the limited understanding of the complexities of the engagement phenomena, the present study analysed these same narratives by utilizing an alternative qualitative method, namely discourse analysis.

Discourse Analysis (DA) comes in many guises and transcends the theoretical perspectives of disciplines as diverse as linguistics, psychology, sociology and anthropology, to name but a few (e.g. Edwards and Potter 1992; Chouliaraki and Fairclough 1999; Harper 2006; Willig 2008). In its broadest sense DA is less interested in narrative detail alone and more, to varying levels of intensity depending on the discipline, interested in how people communicate the identities and roles that they adopt or are positioned into by social contexts. To date DA has been widely applied to important areas of social psychiatry. For example, it has captured how identity and agency is restricted through socially constructed power structures such as diagnostic classifications (e.g. Parker $e t$ al. 1995; Fee 2000), how practitioners and patients position themselves in psychiatric interventions and consultations (Leishman 2004; Mitchell 2009; Ziolkowska 2009) or how mental illness is conveyed through the television and media (e.g. Wilson et al. 2000; Paterson 2007).

The present study introduced a further application of DA, namely the extent and ways that the structure of language can signal people's engagement and disengagement experiences with services and practitioners. To do this, a variant of DA, positioning analysis, was used. Positioning analysis (PA) aims to capture how language, through grammatical markers and other rhetorical (persuasive) devices, positions people in social contexts, e.g. whether they are active or passive, powerful or powerless, victims or perpetrators (Bamberg, 1997, 2000; Harré and van Langenhove 1999; Benwell and Stokoe 2006). By incorporating PA the current study aimed to contribute to our understanding of the psychosocial factors that facilitate or inhibit people's engagement with mental health services in two ways. First, it investigated the role that the structure of people's language serves in communicating psychiatric experiences and narratives of dis/engagement. Specifically it was interested in the ways that language could signal the positioning of self within a therapeutic relationship and how it highlights other important life and psychiatric experiences. Second, as PA was being applied to narratives that were previously extensively analysed with thematic analysis (Priebe et al. 2005) we aimed to evaluate the role that contextualized language analysis, such as PA, can play alongside thematic analysis in health services narrative research.

\section{Method}

\subsection{Sampling}

All participants shared the following common diagnostic characteristics:

(a) a diagnosis of functional psychosis according to ICD-10 (World Health Organisation 1992);

(b) the ability to give informed consent;

(c) absence of a significant organic mental disorder;

(d) absence of a primary diagnosis of substance misuse and dependence;

(e) not requiring an interpreter.

Forty participants were strategically sampled based on their history of engagement with generic mental health services. They had all previously disengaged with secondary mental health services support, e.g. 
had actively missed an outpatient appointment or deliberately ceased taking their medication, and had been referred from a community mental health team to an assertive outreach team (smaller multidisciplinary mental health teams set up to engage the 'difficult-to-engage') as a result of fragmented engagement with services. All participants were contacted via their key workers from nine assertive outreach teams across the London area.

\subsection{Procedure}

Participants were interviewed by a trained researcher who was not involved in their treatment. The unstructured interviews focused on experiences from the time they first came into contact with mental health services and their relationship with services thereafter. Eleven females and 29 males were interviewed (mean age $=40$ years). Thirty-three participants were clinically diagnosed as primarily having schizophrenia or another psychosis related disorder and seven as having psychotic symptoms related to a mood disorder. All interviews were transcribed and originally thematically analysed in a previous study (Priebe et al. 2005) using the qualitative analysis software package QSR Nudist 4. In this study, the transcribed interviews and resultant thematic findings were re-analysed using positioning analysis and the QSR*NVIVO 7 software package.

\subsection{Ethical considerations}

Local NHS ethics approval was successfully gained for all areas of London where interviews took place. The interviews were conducted by the first author and took place in participants' homes or in confidential areas in the assertive outreach teams' premises. All interviewees were outpatients and were judged well enough (by their assertive outreach key worker) to participate in the study. Informed consent was only sought at the time of the interview and participants had the opportunity to withdraw from the study at any time (during or post-interview) without having to explain their withdrawal.

\subsection{Analysis}

An extensive pilot study was undertaken in order to ascertain the discourse analytical approach most likely to capture the linguistic nuances of people's experiences of engagement with mental health practitioners and services. Sixteen of the most thematically rich narratives that related to psychiatric hospital experiences were chosen from the interview corpus of Priebe et al. (2005). Following the pilot study, positioning analysis was chosen as the main method of approach. Positioning analysis captures how people draw on indexical linguistic devices and expressions such as pronouns, grammatical markers and metaphors, to express their view of the world and how they position themselves and others within it (Bamberg 1997, 2000; Harré and van Langenhove 1999; Benwell and Stokoe 2006).

The pilot study showed that metaphor was an important language device used to emotively express positions. For example, it facilitated the communication of passivity within the therapeutic context, e.g. He made me feel, you know, I was a piece of meat and a number; as well as within the wider social context of lost aspirations and life goals, e.g. Its kind of like those people who go to jail and realize the time they've lost. As a result, the use of metaphor was scrutinized in the present study. Our pilot study also identified two other discursive devices, often used in conjunction with metaphor, which facilitated positioning. These were again targeted in the present analysis. The first one was the use of the passive voice. Here, people conveyed their transition from active participant in their day-to-day lives by describing themselves as an object in relation to an action carried out on them by others, e.g. I was stamped with a mental illness. The second device was pronoun use, where people negatively and positively positioned themselves through their use of pronouns. For example, people often exemplified positioning within negative therapeutic relationship by 'lumping' all mental health professionals together in the collective and all powerful they or them, without formal introduction or individualization e.g. They get hold of you, [and] if they have to let you go, they have to let you go slowly.

\subsection{Identifying discursive devices}

Only active metaphors (Goatly 1997) were coded and analysed, as opposed to conventional or dead metaphors. Metaphors were considered active when the language was used outside of its dictionary use (OED), when an understanding of the utterance required the blending of lexical domains, e.g. life and road (Bowdle and Gentner 2005; Zinken 2007) or when the figurative expression was highlighted with the use of 'tuning devices'; phrases such as so to speak, in a way or, kind of, sort of, like, etc., that tend to appear in the proximity of figurative and metaphoric language (Cameron and Deignan 2003). Discussions between coders were used in the first phase of annotation to resolve unclear cases by incorporating the Metaphor Identification Procedure (Pragglejaz Group 2007). 
Metaphors were identified through reading the original Priebe et al. (2005) transcripts and by undertaking a trawl of queries using QSR NVIVO 7 - where metaphoric tuning devices (Cameron and Deignan 2003) were used as specific search terms. In this context the tuning devices increased the efficiency of metaphor identification, ensuring that metaphors were less likely to be missed in the $550+$ pages of transcripts. The other positioning devices of the passive voice and pronoun use were identified by targeting narrative that was likely to elicit discourses of engagement and disengagement. Again NVIVO 7 was used for the task. This time a trawl of the thematically analysed data of Priebe et al. (2005) was undertaken. Here previously identified concrete themes such as negative and positive hospital and psychiatrist experiences, and more abstract ones, such as loss of identity and agency, were focused on. Positioning analysis was then targeted at the respective segments of narratives.

\section{Results}

Table 1: Type and prevalence of the 'turns' incorporating positioning

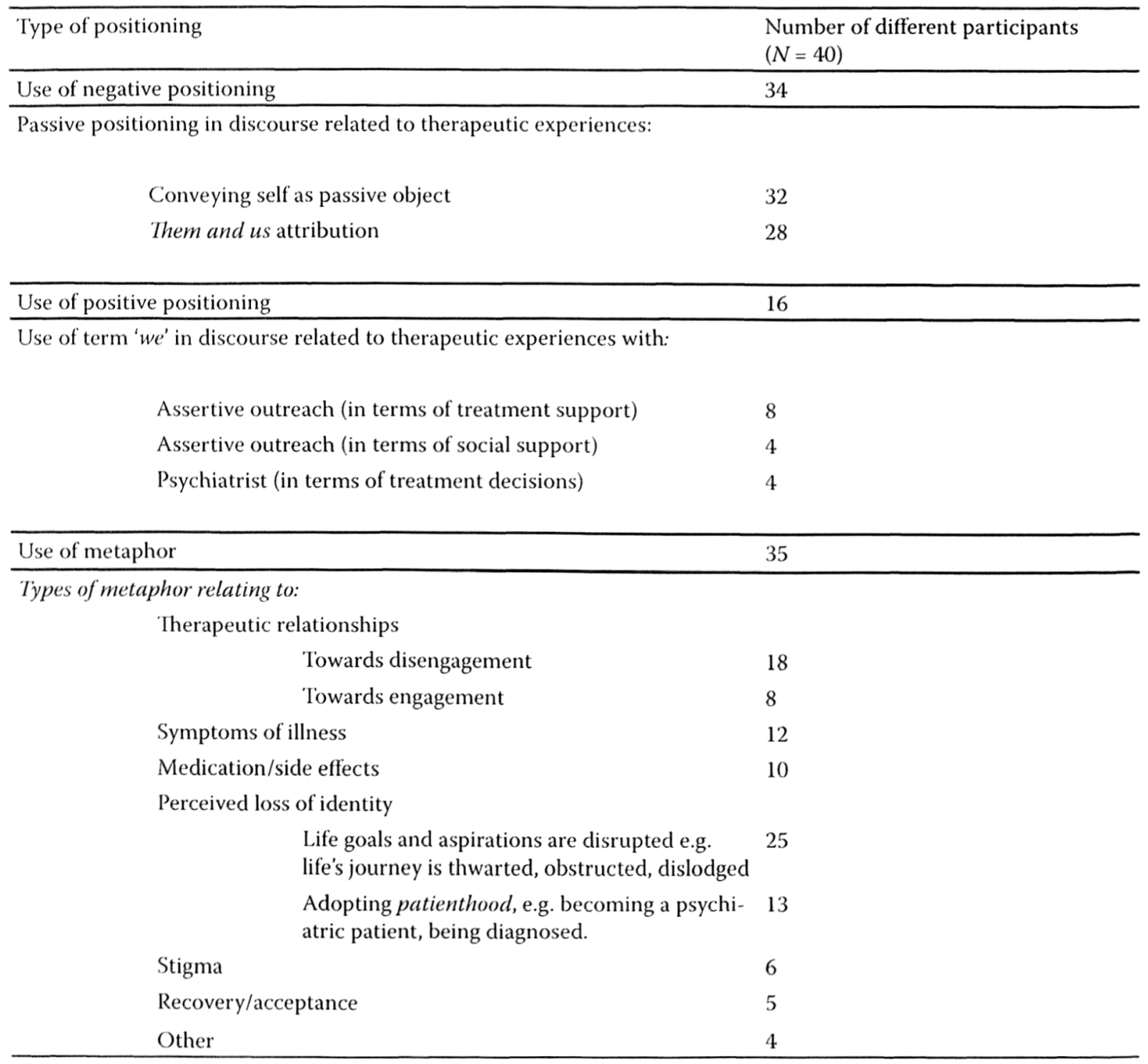

1. A turn is a time during which a single participant speaks before interruption and with minimal overlap and pause (Levinson 1983). In this case it meant responses to questions. It is important to note that within one turn there were often multiple examples of discursive and positioning devices. 
Only two out of the 4.0 participants did not use any of the discursive devices of metaphor, passive voice or them and us attribution in their narratives of disengagement. Table 1 shows that 35 participants used metaphor and imagery to passively position themselves and to convey to the researcher how their lives had been disrupted by mental illness. As can be seen, this metaphoric use of language was not restricted to particular aspects of their illness, treatment or service relationship, but as a means of conveying the whole experience of their psychiatric lives. The table also reports the extent and ways that 34 different participants used other discursive means to position themselves within the therapeutic relationship. When conveying a sense of poor engagement within the therapeutic relationship, 32 participants adopted a passive positioning of self as object and 28 negatively categorized practitioners as a unified and de-individualized body. More positive discursive positioning was far more difficult to identify. When expressed it would often incorporate the personal pronoun we in connection with the therapeutic relationship. Sixteen participants used we to talk about their current therapeutic relationships, although only four out of these 16 discussed psychiatrists using this term.

\subsection{The discourse of disengagement}

\section{The use of metaphor}

One particular category of metaphor used by 25 participants was to passively position themselves in terms of being thwarted in their life goals and aspirations. For example, participants might contrast their lives to a journey; where, despite every effort to remain on a set course, they were inevitably held back, obstructed or dislodged by their illness, treatment or intervening services. Consequently, this impacted on adherence to treatment and engagement in the therapeutic relationship.

I don't know I just feel as if I've derailed off my natural course of life. I've always tried to get back into what

I was, I found that I just can't do it and then I've missed out on so many things because of it. (Int. 36, man aged 22)

Early psychiatric experiences played a crucial role in perceptions of loss of identity. Loss of identity here was metaphorically communicated in terms that helped convey experiences of a transition from independent agent to psychiatric patient $(N=13)$. For example, participants talked about being passively tagged, labelled and even stamped with a mental illness. Early hospital experiences were highly memorable for many participants and metaphor was again an important tool used to negatively position themselves and others in relation to their fear of entering these highly stigmatized environments. The imagery chosen by four female participants related to alienation and experiences of other or collapsing worlds. One moment they were in their known world, where they had their identity and where they understood their roles and their place. Then all of a sudden they were transported to a world that they knew nothing about - a world where they were surrounded by people who were severely mentally ill; a world where they were fundamentally disorientated and scared.

I mean I had some scary thoughts about what a mental hospital was like and that confirmed it, it was quite horrific to see people who are really severely ill, just on another planet. (Int. 21, woman aged 37)

Positioning analysis focuses on how language is contextually used rather than on the content alone. As such, the least rich narratives were as likely to tell us something about important experiences as those that were more articulate and thematically rich. This was evident with the following participant who was excluded from the original pilot analysis, as he was judged by the authors to be economical and guarded in his narrative. Through the use of imagery and repetition, he was still able to elicit a powerful discourse message when asked about his first experience of hospital:

'Hell, that's what I can say. I can't say anything else, hell, hell, hell, hell? (Int. 37, man aged 33)

After the initial shock of finding themselves in a psychiatric hospital, people needed to accustom themselves to the restrictive environments that they now found themselves in. Prison metaphors and analogies were undoubtedly the most common way to describe hospital admissions, with $35 \%$ spontaneously using the term prison to describe previous experiences.

You know that is what I don't like the rules, the silly rules like that door is not allowed to be opened at a certain time ... you're not allowed to do this but you can do that, you know it's like being in a prison. (Int. 11 , woman aged 35 )

\section{Use of the passive voice}

One way used to convey the power imbalance within the therapeutic relationship was the use of the passive voice $(N=32)$ to relay a transition of self as active subject to a self as passive object, a grammatical device often used in conjunction with metaphor. The following participant, for example, uses the passive 
voice to describe his experiences and in doing so foregrounds his lack of agency. He talks about his transformation from an active subject to an object.

We [mother and himself] were fetched to the hospital

... I got taken into a room ... I got led down a cor-

ridor, put into a ward and was just left there. (Int.

20 , man aged 28 )

Similarly, the following female participant used a combination of metaphor and passive voice to position her loss of agency in terms of self and other. She positions herself as an object to express how she was subservient to the power of mental health services in the way she was sectioned and administered to hospital.

I was bounced in and out of [local] hospital until it shut in 1996

I've had CPNs [community psychiatric nurses] in the past, if you tell them the smallest symptom, in my, in my mind, they'd have me binned.

I mean the, the staff seem quite happy to let you rot in bed ... you were very rarely checked to see where you are, what you're doing, how you are, you were just dumped there. (Int. 19, woman aged 39)

\section{Them and us attribution}

The majority of participants $(\mathrm{N}=28)$ at some point positioned the medical professionals as a collective and all-powerful them and themselves as the passive $u s$. For example, the following participant positions all practitioners as a single body of perpetrators; 'they' who use labels to strip other people of their previous identity and position them in a passive category with assigned diagnostic attributes.

they just retreat into labels because of what they see from the outside and this is true of everyone. (Int. 18 , man aged 43)

A more obvious metaphor was sometimes used to express passive positions within the therapeutic relationships with psychiatrists. The following example powerfully captures what it felt like to not be listened to compassionately or be encouraged to be an active participant in dialogues. Here the comparison was of superior and authoritarian beings.

They don't listen because these men rate themselves as gods. (Int. 31, man aged 55)

Similar imagery was used to express poor therapeutic relationships outside of hospital with community practitioners. Here the discourse methods of metaphor and positioning tended to position practitioners as parental rather than God-like.
So I've got two fathers, like bullying me you know. It's not much of a life being controlled, you know, being controlled by your father and all the teams. (Int. 2, man aged 28)

Interestingly, the them and us discourse device was not confined to the positioning of oneself as passive in relation to psychiatrists and nurses. It was also used by some participants $(N=6)$ to passively position other patients in relation to themselves, perhaps as a means of retaining some sense of normality. This is exemplified in the following narrative, which captures how someone can passively position others but still passively position themselves.

I understand, when they [other patients] are not well, their responsibilities are demised and they need to be told what to do like children, um, but on the other hand we don't want to be frog marched up and down. (Int. 21, woman aged 37)

\subsection{The discourse of engagement}

Discourses of engagement were sparse. It was estimated that narratives related to negative experiences of practitioners and treatment outweighed positives experiences by a ratio of approximately $4: 1$. Relative to this, positive positioning of selves and practitioners were difficult to identify.

\section{Positive positioning of therapeutic relationships}

Participants were less likely to use them and us discourse when more positive experiences of therapeutic relationships were expressed. This was demonstrated by the analysis of narratives of participants where they contrasted their experiences of poor and good therapeutic relationships. A particular important discourse device was the usage of the personal pronoun we, which was used to convey improved therapeutic relationships with generic practitioners $(N=8)$ and psychiatrists $(N=4)$.

In the following example, a participant who had, over many years, found it very difficult to maintain consistent contact with services talks about a traumatic hospital experience.

And when I was nineteen I got admitted to the local psychiatric unit in Bxx, and I had the most dreadful treatment ... They drugged me up to my eyeballs on about two major, major anti-psychotics. (Int. 19, woman aged 39)

Discursively, the woman identifies her loss of agency by positioning all mental health service professionals within the Unit as the people who administered the excessive drugs and utilizes metaphor to further 
emphasize the extent of the perceived medication abuse. This can be contrasted to the description of her present community psychiatric nurse (CPN):

I think he's been my CPN for at least 5 years now. It's absolutely brilliant. I mean he's, we've got the right balance. (Int. 19, woman aged 39 )

Here the same woman's use of positioning is positive and expresses her ability to be active within the therapeutic relationship rather than passive. She implies mutuality in their professional relationship by the introduction of we've (following a thoughtful and deliberate change from the use of he's) and her reference to balance.

Another participant also used we to convey how her therapeutic relationship developed. Here she describes how her relationship with her present $\mathrm{CPN}$, who she earlier metaphorically compared to a controlling second mother, progressed over time. In her discourse here she contrasts passive you and active we pronouns to convey her transition to communicative partner.

The thing is we go out for coffees and we just, um, we just chat about anything and everything really, and that's what's nice about it now, whereas before it was, 'Are you well?', um, you know, 'Have you been taking your medication?', ... you know the general, 'I'm from the hospital, you know, you're the patient type of thing.' (Int. 8, woman aged 23)

The term 'more like friends' was used by four participants to condense the attributes that went up to make a good therapeutic relationship with community mental health workers. The term seemed to neatly summarize how therapeutic relationships could grow in strength and balance.

We've become more like friends now, I find she is very kind, very caring, very helpful, insightful as well. It's nice to have someone to talk with on the same level now. (Int. 23, woman aged 48 )

Although negative positioning in relation to therapeutic relationships with psychiatrists was found in abundance, positive discourse in this respect was infrequent. The use of the personal pronoun we occurred in only four narratives. Where found, the more 'engaged' therapeutic relationships with psychiatrists were again metaphorically talked about in terms of achieving a balance, a level or a two-way process. For example, in the following example positioning through metaphor and pronoun use is used to convey how, over time, the participant made the transition from passive recipient to active participant in his therapeutic communication and treatment.
I had Dr Z I didn't have much of a chance to tell him how I felt or anything, it was just, "Take this and take that' ... but with Dr Y it changed. At first it was very, 'I want you to do this that and the other', but now he spends more time asking me what I think about what I am taking, what I think will help, and I will give him suggestions and he either agrees or disagrees with it ... It is more a two-way thing, which is more beneficial for me because I feel I am starting to get a say in my treatment. (Int. 35 , man aged 39)

\section{Discussion}

The focus of the study was to examine the narratives of patients who had previously found it difficult to engage with mental health services, and to ascertain how the form of language, through grammatical and other rhetorical (persuasive) devices, was used to convey dis/engagement experiences. In a former related study (Priebe et al. 2005), thematic analysis of the same data identified that disengagement was essentially the struggle to remain active agents in their lives and treatment, and that re-engagement, where possible, incorporated facilitating the return of agency in this regard. The present study corroborated these findings. Through the power of positioning (Shotter 1989; Davies and Harré 1990; Bamberg 1997, 2000; Benwell and Stokoe 2006), participants consistently emphasized the impact the interrelated experiences of loss of identity and agency had on their lives and their willingness to engage with services. In particular, the analysis of narratives showed how participants drew on the discursive resources of metaphor, the passive voice and them and us attribution, to help make sense of, and communicate with emotional depth, their struggle to maintain or regain their familiar identity and their efforts to resist what they regarded as the transition from independent agent to a patient, i.e. an object of agency in the grammatical sense.

Metaphors were consistently used to describe the transition from active subjects to passive objects in their psychiatric lives. Participants talked about hospital experiences with the most emotion, using an extensive and powerful array of metaphors to describe their psychiatric experiences and the trauma related to their stay. In particular their expression of fear as they entered psychiatric hospitals through their consistent, detailed and thoughtful comparisons of hospital to other worlds and prisons, further emphasized the extent that they felt they had been stripped of their identity and agency (Goffman 1991). 
Throughout the interviews participants consistently positioned themselves in the passive voice as objects that were dealt with by mental health services, either metaphorically, e.g. I was bounced in and out of hospital, or literally, e.g. we were fetched to the hospital. Equally, discourse conveyed how patients were passively stamped with a diagnosis or dismissively treated like an alien or a piece of meat by their psychiatrists.

The use of metaphor to convey the emotive categorization and positioning of mental health services as the all-powerful thern and patients as the passive us was another important discourse device used to convey further features of loss of identity and agency. Participants compared psychiatrists to gods, or community practitioners to controlling parents. Participants also used metaphor and imagery to explain the more subtle ways in which they were positioned within the them and us dyad. They talked in terms of their disappearance or detachment into silence, as their only means of retaining an element of control within a therapeutic relationship. This might be an example of what Goffman termed 'removal activities', whereby patients re-establish a sense of autonomy and identity by distancing themselves from their situation as a patient:

Our sense of being a person can come from being drawn into a wider social unit [where as] our sense of selfhood can arise through the little ways we resist the pull. (Goffman 1991: 280)

Priebe et al. (2005) concluded that disengagement and engagement with mental health services were opposite sides of the same coin and that a partnership model, where an element of active participation was handed back to the patient, was essential to the engagement process. Over and above an understanding of what facilitates engagement with mental health services, the present study has provided additional insights into the point at which the return of agency was facilitated within the therapeutic relationship. Most specifically, a close examination of the grammar, metaphor and phraseology used by participants has enabled us to pinpoint when people with severe mental illness make the shift from passive references of themselves such as being fetched, led, left and bounced, and redefine and position themselves as active participants within what they perceive to be balanced and mutual therapeutic relationships through their use of terms such as we, talking on a level, more like friends and a two-way process.

\subsection{Limitations of the study}

With over 550 pages of transcript, targeted discursive devices may have been missed. Further, there may be other possible interpretations of the same data. For example, in some instances the categorical positioning of the diverse mental health service professionals as the collective they may have occurred simply because the participant assumed the interviewer knew the type of professional they were referring to, or that they did not recognize the distinction between professionals. In addition, there was no means of gaining a baseline of the participants' use of metaphor or the passive voice in more neutral contexts. However, the strength of the design was that we focused on participants with manifest difficulties with services engagement, and were able to compare their use of language in relation to their own negative and positive psychiatric experiences. This and the fact that the PA findings were corroborated by earlier thematic analysis (Priebe et al. 2005) means that regardless of the mentioned limitations, the study does demonstrate in-built as well as certain external validity.

\subsection{Practical implications of the study}

The vast majority of narratives were articulate and, apparently, well rehearsed. Participants appeared to have lived and relived the impact of mental illness, and, in doing so, often became coherent and at times expert narrators of their experiences as mental health patients. An important message from this research is that, consciously or unconsciously, participants were driven to use such strategies to convey the importance of losing their ability to be active participants in a known and preferred world and their distress at being thrown into a world of passivity, constraints and alienation. Such positioning devices may serve not only to portray the essence of these experiences to others but also, perhaps, to help conceptualize them to the participants themselves.

As well as flagging levels of therapeutic engagement that need to be noted, such language use may also signal other clinical implications. It is important to remember that the discursive devices used were not confined to experiences related to psychiatric therapeutic relationships but used to describe the many other areas of a psychiatric experience that impacted on participants' lives, e.g. symptoms, medication effects and experience of stigma (see Table 1). As such, the signalling of emotive experiences through positioning devices may afford wider therapeutic possibilities in terms of the recovery of agency and identity (e.g. 
White 1995; Roberts 2000). First, they can draw the attention of the clinician to the fact that the narrator is using them. Second, they offer the clinician and narrator the potential to explore the reasoning and meaning behind them. For example, metaphoric talk about being dislodged from a rail, which is fixed, may have different implications to that of dislodgement from a path, which is not necessarily fixed. Lastly, they afford the opportunity to reframe narrative positions in order to redefine situations and develop personal agency in their lives (e.g. White 1995).

A methodological strength of the study was that important confounds were limited by the fact that two distinct qualitative methods were applied and contrasted using identical data and, in part, analysed by the same co-authors. As such, we believe this puts us in a strong position to critically evaluate the role that discourse analysis in the form of positioning analysis can play alongside thematic analysis in health services narrative research.

First, our findings showed that positioning devices added emotional depth to the conveyance of a person's sense of engagement or disengagement with psychiatric services. In doing so, PA demonstrated it can strengthen research based on narratives of relived experiences, in that it has the potential to signal emotionally charged episodes that can be explored in the interview context or, retrospectively, in the qualitative analysis. A further strength of PA was that it was less time consuming than thematic analysis. In the original Priebe et al. (2005) study an additional six months funding was needed (and granted by the Department of Health) to finish the project, due in large part to the unforeseen length of time needed for rigorous grounded thematic analysis. The analytical process here was undoubtedly facilitated by the qualitative database software used, which enabled the researchers to focus their efforts on language use in specific therapeutic and social contexts. A further benefit of the PA method over thematic analysis was that the narratives did not need to be thematically rich in order to elicit important information about the psychiatric experience of the narrator.

Perhaps the largest question that hangs over the use of PA is what role, beyond a synergetic one, it can play in health services projects where evidence of underlying motives and processes are needed. If, for example, the object of the research (or clinical) exercise is to highlight, through their use of language, people's positioning within a therapeutic context, then PA is undoubtedly capable of fulfilling the task. If, on the other hand, we want to fully critically explore the underlying processes that lead to the positions that people are assigned to, or adopt, then knowledge and interpretation of thematic content is also likely to be needed.

\section{Conclusion}

In addition to previous applications of discourse analysis (e.g. Parker et al. 1995; Wilson et al. 2000; Leishman 2004; Paterson 2007; Ziolkowska 2009) our findings introduce new insights into how language positions people in the psychiatric context. By incorporating linguistic structure, rather than thematic content alone, discourse analysis, in the form of positioning analysis, has the potential to highlight the emotional emphasis that people place on important life and therapeutic experiences. As such, the most limited communication within a clinical or research narrative context can signal important shifts in the therapeutic process which are either positive or indicative of therapeutic breakdown.

\section{References}

Bamberg, M. (1997). Positioning through structure and performance. Journal of Narrative and Life History 7 (1-4): 335-342.

Bamberg, M. (2000). Critical personalism, language development. Theory E Psychology 10 (6): 749-767. doi: $10.1177 / 0959354300106003$

Benwell, B. and Stokoe, E. (2006). Discourse and Identity. Edinburgh: Edinburgh University Press.

Bowdle, B. and Gentner, D. (2005). The career of metaphor. Psychological Review 112 (1): 193-216. doi:10.1037/ 0033-295X.112.1.193

Braun, V. and Clarke, V. (2006). Using thematic analysis in psychology. Qualitative Research in Psychology 3 (2): 77 101. doi:10.1191/1478088706qp063oa

Burns, T., Creed, F., Fahy, T., Thompson, S., Tyrer, P. and White, I. (1999). Intensive versus standard case manage ment for severe psychotic illness: A randomised trial. UK 700 Group. Lancet 353 (9171): 2185-2189. doi: 10.1016/S0140-6736(98)12191-8

Cameron, L. and Deignan, A. (2003). Combining large and small corpora to investigate tuning devices around metaphor in spoken discourse. Metaphor and Symbol 18 (3): 149-160. doi:10.1207/S15327868MS1803_02

Chouliaraki, L. and Fairclough, N. (1999). Discourse in Late Modernity: Rethinking Critical Discourse Analysis. Edinburgh: Edinburgh University Press.

Davies, B. and Harré, R. (1990). Positioning: The discursive production of selves. Journal for the Theory of Social Behaviour 20 (1): 43-63. doi:10.1111/j.1468-5914.1990. tb00174.x 
Department of Health (2001). Safety first: Five-year Report of the National Confidential Inquiry into Suicide and Homicide by People with Mental Illness. Retrieved 10 March 2010, from http://www. dh.gov.uk/en/Publicationsandstatistics/Publications/ PublicationsPolicyAndGuidance/DH_4006679

Edwards, D. and Potter, J. (1992). Discursive Psychology. London: Sage Publications.

Fee, D. (2000). Pathology and the Post Modern: Mental Illness as Discourse and Experience. Thousand Oaks, CA: Sage Publications.

Fenton, W., Blyler, R. and Heinssen, R. (1997). Determinants of medication compliance in schizophrenia: empirical and clinical findings. Schizophrenia Bulletin 23 (4): 637-651.

Goatly, A. (1997). The Language of Metaphors. London: Routledge.

Goffman, E. (1991). Asylum: Essays on the Social Situation of Mental Patients and Other Inmates. London: Penguin.

Harper, D. (2006). Discourse analysis. In M. Slade and S. Priebe (eds) Choosing Methods in Mental Health Research: Mental Health Research from Theory to Practice 47-67. London: Routledge.

Harré, R. and van Langenhove, L. (1999). Positioning Theory. Oxford: Blackwell.

Leishman, J. L. (2004). Talking the talk: A discourse analysis of mental health nurses talking about their practice. International Journal of Psychiatric Nursing Research 10 (1): 1136-1145.

Levinson, S. (1983). Pragmatics. Cambridge: Cambridge University Press.

Mitchell, P. F. (2009). A discourse analysis on how service providers in non-medical primary health and social care services understand their roles in mental health care. Social Science and Medicine 68 (7): 1213-1220. doi:10.1016/j.socscimed.2009.01.001

Mueser, K., Bond, G., Drake, R. and Resnick, S. (1998). Models of community care for severe mental illness: A review of research on case management. Schizophrenia Bulletin 24 (1): 37-74.

O'Brien, A., Fahmy, R. and Singh, S. P. (2008). Disengagement from mental health services. A literature review. Social Psychiatry and Psychiatric Epidemiology 44 (7): 558-568. doi:10.1007/s00127-008-0476-0

Parker, I., Georgaca, E., Harper, D., McLaughlin, T. and Stowell-Smith, M. (1995). Deconstructing Psychopathology. London: Sage Publications.

Paterson, B. (2007). A discourse analysis of the construction of mental illness in two UK newspapers from 19852000. Issues in Mental Health Nursing 28 (10): 10871103. doi:10.1080/01612840701581206

Pragglejaz Group (2007). A practical and flexible method for identifying metaphorically-used words in discourse. Metaphor and Symbol 22 (1): 1-39. doi:10.1207/s15327 868ms2201_1

Priebe, S., Fakhoury, W. and Watts, J. (2003). Assertive Outreach teams in London: Patient characteristics and outcomes. Pan-London Assertive Outreach Study,
Part 3. British Journal of Psychiatry 183 (2): 148-154. doi:10.1192/bjp.183.2.148

Priebe, S., Watts, J., Chase, M. and Matanov, A. (2005). Processes of disengagement and engagement in assertive outreach patients: Qualitative study. British Journal of Psychiatry 187 (5): 438-443. doi:10.1192/ bjp. 187.5 .438

Roberts, G. (2000). Narrative and severe mental illness: What place do stories have in an evidence-based world? Advances in Psychiatric Treatment 6 (6): 432-441. doi:10.1192/apt.6.6.432

Sainsbury Centre for Mental Health (1998). Keys to Engagement. London: Sainsbury Centre for Mental Health Publication.

Shotter, J. (1989). Social accountability and the social construction of 'You'. In J. Shotter and K. Gergen (eds) Texts of Identity 133-151. London: Sage Publications.

Slade, M. and Priebe, S. (2006). Choosing Methods in Mental Health Research: Mental Health Research from Theory to Practice. London: Routledge.

Strauss, A. and Corbin, J. (1998). Basics of Qualitative Research: Techniques and Procedures for Developing Grounded Theory. Thousand Oaks, CA: Sage Publications.

White, M. (1995). Re-authoring Lives: Interviews and Essays. Adelaide: Dulwich Centre Publications.

World Health Organization (1992). International Classification of Diseases. 10th Revision. Geneva: WHO.

Williams, B. (2002). The role of qualitative methods in evidenced-based mental health care. In S. Priebe and M. Slade (eds) Evidence in Mental Health Care 109-125. Hove: Brunner-Routledge.

Willig, C. (2008). Introducing Qualitative Research in Psychology (2nd edn). Buckingham: Open University Press.

Wilson, C., Nairn, R., Coverdale, J., Panapa, F. and Panapa, A. (2000). How mental illness is portrayed in children's television: A prospective study. The British Journal of Psychiatry 176 (5): 440-443. doi:10.1192/ bjp.176.5.440

Zinken, J. (2007). Discourse metaphors: The link between figurative language and habitual analogies. Cognitive Linguistics 18 (3): 445-466. doi:10.1515/COG. 2007.024

Ziolkowska, J. (2009). Positions in doctors' questions during psychiatric interviews. Qualitative Health Research 19 (11): 1621-1631. doi:10.1177/1049732309350685

Mike Chase works in Psychology, where he lectures in qualitative research methods. He has over fifteen years' experience of working with people with severe mental illness and disability, and a strong theoretical interest in pragmatism and other non-dualist perspectives on human existence. He is currently merging his practical background and theoretical interests in a PhD that is exploring how contemporary 
systems of psychiatric practice exacerbate the negative experiences of people living with severe mental illness. Address for correspondence: Department of Psychology, University of Portsmouth, King Henry I Street, Portsmouth PO1 2DY, UK. Email: mike. chase@port.ac.uk

Jörg Zinken received his $\mathrm{PhD}$ in Linguistics from the University of Bielefeld and is currently Senior Lecturer in Psychology at the University of Portsmouth. His research interests include the use of metaphor in science and in narrative. Address for correspondence: Department of Psychology, University of Portsmouth, King Henry I Street, Portsmouth PO1 2DY, UK. Email: joerg.zinken@port.ac.uk

Alan Costall is Professor of Psychology at the University of Portsmouth. His research applies a contextualist or 'ecological' approach to a wide range of topics. He recently published Doing Things with Things: The Design and Use of Everyday Objects with Ole Dreier (2006, Ashgate) and Against Theory of Mind with Ivan Leudar (2009, Macmillan Palgrave). Address for correspondence: Department of Psychology, University of Portsmouth, Portsmouth, PO1 2DY, UK. Email: alan.costall@port.ac.uk
Jay Watts received her DClinPsy from the University of East London, and went on to several senior clinical posts in the British National Health Service. Her research interests focus on discourse analysis of family-talk in psychosis and Lacanian psychoanalysis. She currently works as a clinical lecturer at City University, and runs a private practice. Address for correspondence: Department of Counselling Psychology, City University, Northampton Square, London, EC1V OHB, UK. Email: jay.watts.1@city.ac.uk

Stefan Priebe qualified as a psychiatrist and psychotherapist at the Free University Berlin. He has been Chair for Social and Community Psychiatry at Queen Mary, University of London since 1997. Stefan is currently Director of a Research Unit focusing on psychosocial processes and outcomes of mental health care and is the PI on a number of national and international studies. He has produced $350+$ peer-reviewed publications. Understanding therapeutic relationships and patient-clinician communication is core to his research activities. Address for correspondence: Unit for Social and Community Psychiatry, Newham Centre for Mental Health, London E13 8SP, UK. Email: s.priebe@ qmul.ac.uk 